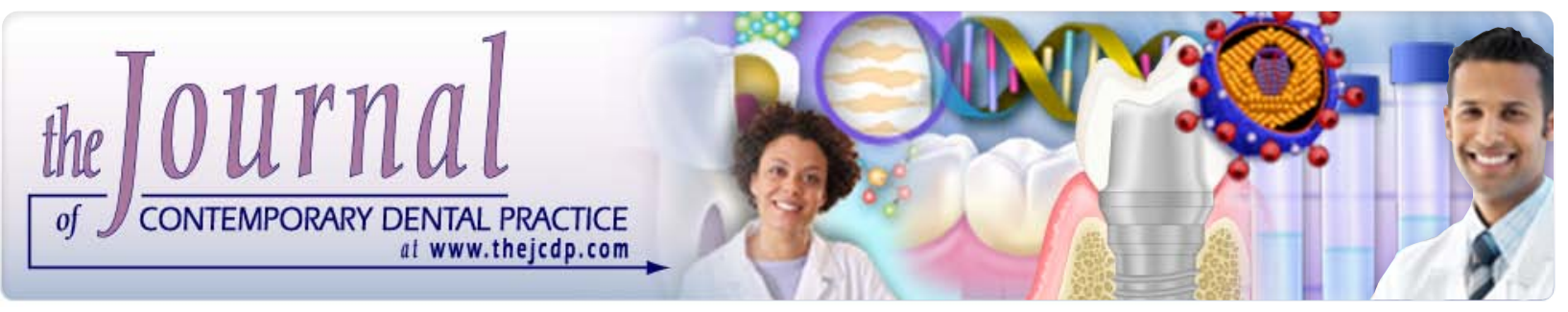

\title{
Effect of Postoperative Bleaching on Marginal Leakage of Resin Composite and Resin-Modified Glass lonomer Restorations at Different Delayed Periods of Exposure to Carbamide Peroxide
}

Horieh Moosavi, DDS, MS; Marjaneh Ghavamnasiri, DDS, MS; Vahideh Manari, DDS

\section{Abstract}

Aim: To evaluate the effect of dental bleaching with carbamide peroxide at different exposure times on the microleakage of resin composite and resin-modified glass ionomer restorations after placement in extracted human teeth.

Methods and Materials: 120 Class V cavity preparations were placed at the cementoenamel junction (CEJ) of human teeth. Half of the cavities were restored with Filtek P60 resin composite(C) and the other half were restored with Fuji II LC resin-modified glass ionomer $(\mathrm{G})$. Each group was randomly divided into four subgroups $(n=15)$. Groups $\mathrm{C} 1$ and $\mathrm{G} 1$ were not bleached and stored in artificial saliva at $37^{\circ} \mathrm{C}$ to serve as control groups, while in Groups C2 and G2, C3 and G3, and $\mathrm{C} 4$ and G4 specimens were exposed to a $15 \%$ carbamide peroxide gel for one day, one week, and two weeks, respectively, following the placement of restorations. Microleakage was assessed using the dye penetration method. Data were analyzed using the Kruskal-Wallis and Wilcoxon tests $(p=0.05)$.

Results: The Kruskal-Wallis test showed no significant difference among all groups of composite or glass ionomer restorations with either enamel or dentinal margins with regard to microleakage ( $p>0.05)$. The Wilcoxon test revealed more marginal leakage in the enamel/ glass ionomer margins than the enamel/ composite margins $(p<0.05)$. In comparisons within each group, the Wilcoxon test showed

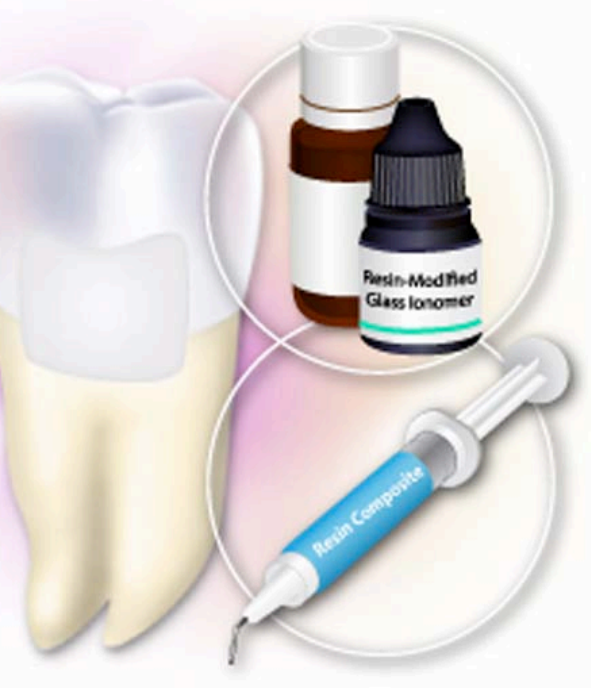

there was more microleakage in dentinal margins of composite restorations than in the enamel margins in the test groups $(p<0.05)$. The dentinal margins of the glass ionomer in control groups showed more leakage than the enamel margins, but after the bleaching procedure all experimental groups showed statistically similar microleakage in both the enamel and dentinal margins ( $p>0.05)$.

Conclusions: Postoperative bleaching with carbamide peroxide could increase microleakage in the dentinal margins of composite and the enamel margins of resin-modified glass ionomer restorations. 
Clinical Significance: Rebonding of resin composite restorations should be considered following bleaching with $15 \%$ carbamide peroxide in order to reseal the margins. Resin-modified glass ionomer is not suitable as a filling material before bleaching because of its susceptibility to increased microleakage.

Keywords: Microleakage, postoperative bleaching, resin-modified glass ionomer, resin composite

Citation: Moosavi H, Ghavamnasiri M, Manari V. Effect of Postoperative Bleaching on Marginal Leakage of Resin Composite and Resin-Modified Glass lonomer Restorations at Different Delayed Periods of Exposure to Carbamide Peroxide. J Contemp Dent Pract [Internet]. 2009 Nov; 10(6):009-016. Available from: http://www.thejcdp. com/journal/view/volume10-issue6-moosavi.

\section{Introduction}

Discolored anterior teeth present a serious esthetic problem. Dental bleaching should be the first step taken in treatment since it is the most conservative one. ${ }^{1}$ The widespread use of bleaching agents has resulted in concerns regarding their oxidizing effect on soft tissue, dental structures, and restorations. ${ }^{2}$ There are some controversial findings regarding the effect of bleaching on surface texture, fracture toughness, hardness, and flexural strength of dental hard tissues. ${ }^{3-7}$ The influence of various bleaching agents on the physical properties and surface morphology of different restorative materials also has been investigated. $\frac{6-10}{}$

None of the above mentioned studies investigated the extent to which the induced properties increased surface roughness and reduced the surface hardness of the tested materials and thus created the need for replacement of existing restorations after bleaching to ensure longevity of the restorations. ${ }^{11}$ Therefore, it remains speculative as to whether these changes in dental hard tissues and materials are relevant under clinical conditions. Two studies reported the postoperative contact of composite restorations to various concentrations of carbamide peroxide gel adversely affected the marginal seal of Class $\mathrm{V}$ composite restorations with enamel margins. ${ }^{12,13}$ Crim $^{14}$ found postoperative bleaching led to

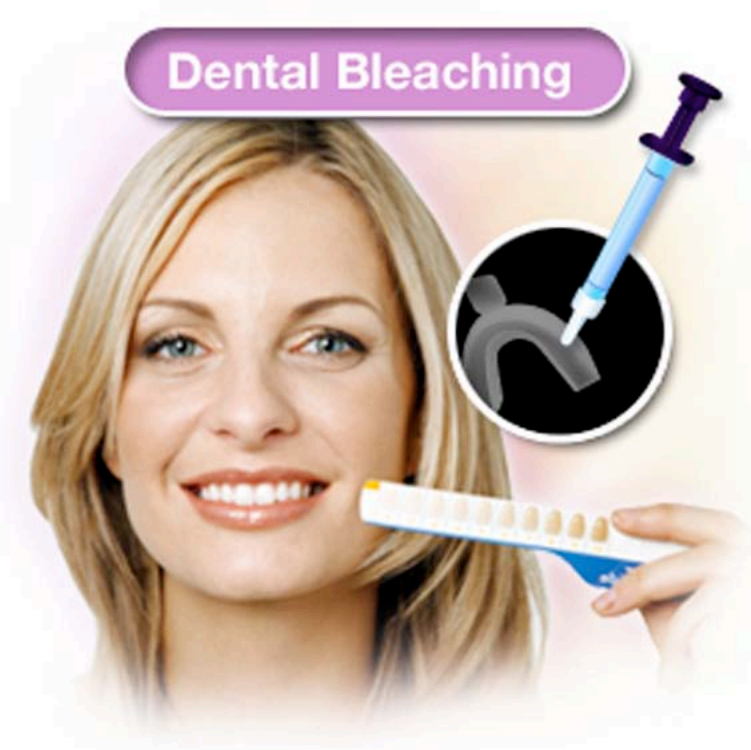

increased microleakage rates at both enamel and dentinal margins of composite restorations. White et al. ${ }^{15}$ found that immediate postoperative bleaching with $20 \%$ carbamide peroxide gel, $6 \%$ hydrogen peroxide, and $19 \%$ percarbonate gel for 14 days had no influence on microleakage of Filtek composite bonded with Scotchbond 1 at the occlusal margins of the Class 1 restorations.

Only one previous study addressed the impact of postoperative bleaching on restorations fabricated with polyacid-modified resin-based composites and resin-modified glass ionomer revealed no deterioration of the enamel marginal seal. ${ }^{13}$

In some instances, there are carious and/or noncarious cervical lesions that should be restored before vital bleaching. Therefore, the aim of this study was to investigate the effect of different time periods of postoperative vital bleaching with $15 \%$ carbamide peroxide on marginal leakage of recently placed resin composite and resin-modified glass ionomer restorations.

The null hypotheses of this study regarding microleakage were as follows:

1. There is no significant difference in leakage among enamel margins of restorations in the test groups.

2. There is no significant difference in leakage among dentinal margins of restorations in the test groups.

3. There is no significant difference in leakage between enamel and dentinal margins within each group. 


\section{Methods and Materials}

A total of 120 sound human third molars extracted within the previous three months were selected for this study and stored at $100 \%$ humidity. First, the teeth were sterilized and then cleaned with a water/pumice slurry using rubber prophylaxis cups in a conventional speed handpiece. A Class $\mathrm{V}$ cavity with the occlusal margin in enamel and the cervical margin located $1 \mathrm{~mm}$ below the cementoenamel junction was prepared on the buccal surfaces of each selected tooth. Cavity dimensions were $3.0 \mathrm{~mm}$ of mesiodistal width and $2.0 \pm 0.5 \mathrm{~mm}$ of occlusogingival length. The depth of the cavities was approximately $2.0 \pm 0.5 \mathrm{~mm}$ calibrated with a premarked periodontal probe. Cavities were prepared with an ISO inverted cone bur (No.014 SS, White Burs, Inc., Lakewood, NJ, USA) and a straight fissure bur (No.010 SS, White Burs, Inc. Lakewood, NJ USA). A 0.5 mm bevel was placed on the cavosurface occlusal margins. The specimens were assigned to two groups ( $n=60)$ according to the materials used to restore them. Specimens in Group C were restored with Filtek P60 resin composite (3M ESPE Dental Products, St Paul, MN, USA). To fabricate the resin composite restorations, the Single Bond total-etch adhesive system (3M ESPE, St. Paul, MN, USA) was used according to the manufacturer's instructions prior to placing the resin composite in 1.0-mm-thick increments. Group $\mathrm{G}$ specimens were restored with a resinmodified glass ionomer cement (Fuji II LC, GC Corporation, Tokyo, Japan). The cavities received surface treatment with $40 \%$ polyacrylic acid (Durelon, 3M ESPE) applied to the enamel

\section{Class V Cavity Preparation}

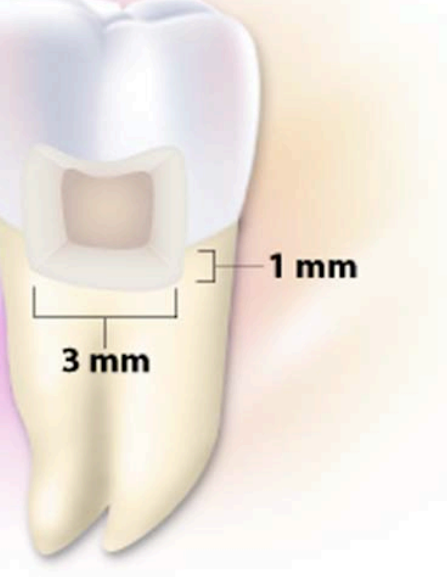

and dentin with a light scrubbing motion for 10 seconds. The cavities were then rinsed for 20 seconds and gently air dried with absorbent paper to keep the tooth surface moist. Afterwards, the standard powder/liquid ratio of the restorative system was dispensed and mixed as specified by the manufacturer. The resulting mixture was inserted into the cavity in one increment.

The two restorative materials were light cured as specified by the manufacturers using a visible light curing unit (Optilux 500, Demetron-Kerr, Orange, CA, USA) with a $500 \mathrm{~mW} / \mathrm{cm}^{2}$ output. The restorations were finished using sof-Lex discs (3M ESPE, St. Paul, MN, USA).

Each group was then divided into four subgroups of 15. Subgroup 1 ( $\mathrm{C} 1$ and $\mathrm{G} 1$, serving as control groups) was not bleached and was stored in artificial saliva (Orafaee Pharmacy Ltda., Mashhad, Iran) at $37^{\circ} \mathrm{C}$ for one day. Subgroups 2 (C2, G2), 3 (C3, G3), and 4 (C4, G4) were stored in artificial saliva for one day, one week, and two weeks respectively. Then they were exposed to a $15 \%$ carbamide peroxide gel (Opalescence Tooth Whitening Gels, Ultradent Products Inc., South Jordan, UT 84095, USA) for eight hours per day for up to 14 days.

All of the specimens were sealed with sticky wax except for a 1-mm-diameter ring surrounding the restorations. The teeth were subjected to a dye solution of $0.5 \%$ basic fuchsin for $24 \mathrm{hrs}$ at $37^{\circ} \mathrm{C}$. The wax was then removed and the specimens were encased in an epoxy resin to create blocks. The resin blocks were sectioned buccolingually through the embedded teeth using a low-speed diamond saw (Isomet, Buehler Ltd., Lake Bluff, IL, USA) to create two test specimens each with exposure of the tooth-restoration interface from the cavosurface margin to the pulpal wall. Microleakage was then assessed using a stereomicroscope (Olympus Co., Tokyo, Japan) at 30x magnification.

Marginal leakage was scored as follows:

$0=$ no dye penetration,

$1=$ dye penetration into half of the extension of the occlusal or gingival walls,

$2=$ dye penetration into complete extension of the occlusal or gingival walls,

$3=$ dye penetration into the axial wall. 
Data were analyzed using the Kruskal-Wallis nonparametric statistical analyses for comparision of data between groups and the Wilcoxon test for comparison of leakage between enamel and dentinal margins within each group as well as for comparison of microleakage of glass ionomer and resin composite restorations $(p=0.05)$.

\section{Results}

FS and SBS rebonding results are reported Frequency scores of marginal leakage for composite and glass ionomer restorations are presented in Table 1.

Among the composite restorations, the control subgroup (C1) had 10 restorations with enamel margins and 9 with dentinal margins that showed no marginal leakage and there was no significant difference from the restorations in the other experimental composite resin subgroups (KruskalWallis $p=0.67$ and $p=0.225$ respectively for enamel and dentinal margins) (Table 1, Figures 1 and 2).

In the control group of glass ionomer restorations, 6 of 15 restorations in enamel margins and only two restorations in dentinal margins showed no dye penetration. These groups also showed no significant difference with their experimental groups (Kruskal-Wallis $p=0.257$ and $p=0.362$ respectively for enamel and dentinal margins (Figure 3 ).

There were significant differences between the enamel margins of composite and glass ionomer restorations (Wilcoxon $p=.000$ ), but no differences

\section{Table 1. Marginal leakage scores of composite and resin-modified glass ionomer restoration groups.}

\begin{tabular}{|c|c|c|c|c|c|c|c|c|}
\hline \multirow{3}{*}{ Scores } & \multicolumn{4}{|c|}{$\begin{array}{l}\text { Composite }(n=60) \\
\text { Subgroups }\end{array}$} & \multicolumn{4}{|c|}{$\begin{array}{c}\text { Glass lonomer }(n=60) \\
\text { Subgroups }\end{array}$} \\
\hline & C1 & $\mathrm{C} 2$ & C3 & C4 & G1 & G2 & G3 & G4 \\
\hline & Ena/Dent & Ena/Dent & Ena/Dent & Ena/Dent & Ena/Dent & Ena/Dent & Ena/Dent & Ena/Dent \\
\hline 0 & $10 / 9$ & $12 / 5$ & $11 / 5$ & $9 / 4$ & $6 / 2$ & $3 / 2$ & $8 / 5$ & $5 / 4$ \\
\hline 1 & $3 / 3$ & $1 / 4$ & $2 / 0$ & $2 / 2$ & $3 / 2$ & $4 / 3$ & $4 / 2$ & $5 / 4$ \\
\hline 2 & $1 / 0$ & $0 / 0$ & $1 / 4$ & $1 / 4$ & $1 / 3$ & $1 / 3$ & $1 / 1$ & $1 / 4$ \\
\hline
\end{tabular}

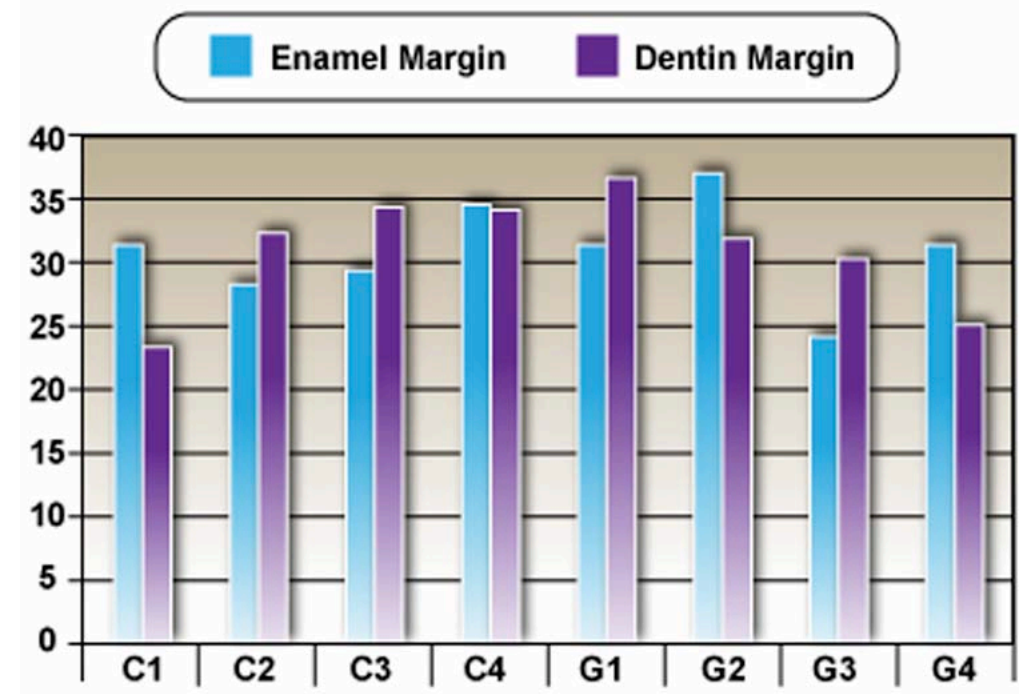

Figure 1. Comparison of dye penetration in enamel and dentinal margins of the test groups. 


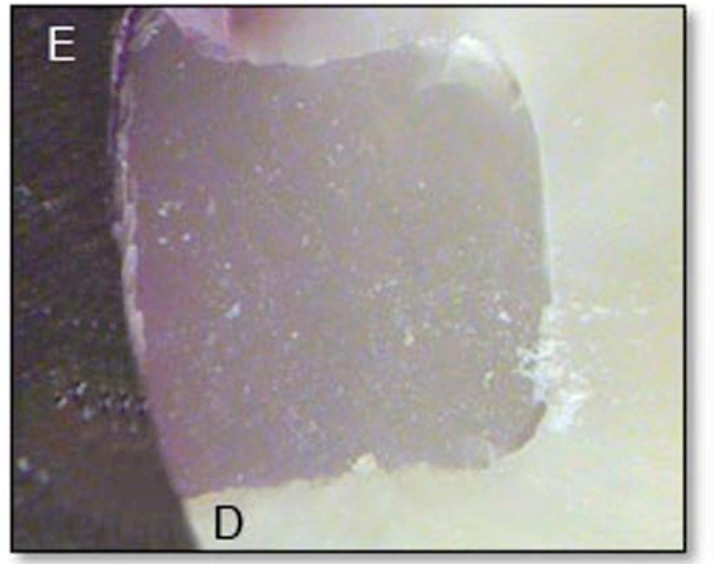

Figure 2. Resin composite (control group): No dye penetration was observed in enamel $(E)$ and dentinal (D) margins (30x magnification).

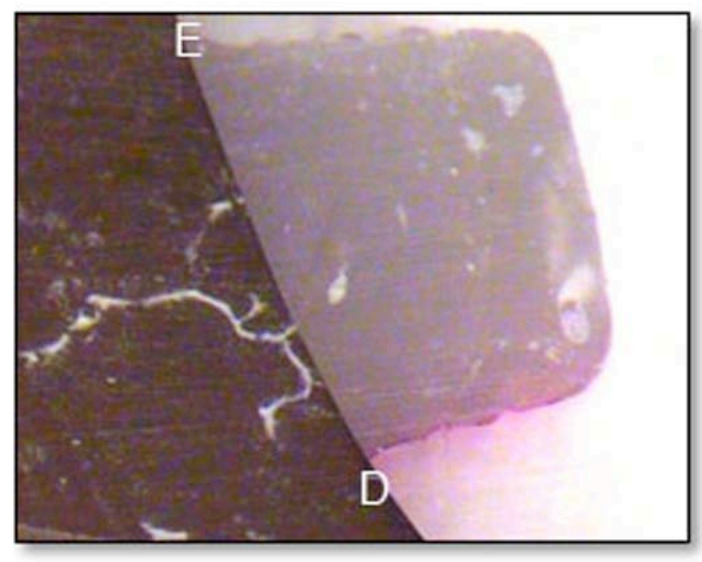

Figure 3. Resin-modified glass ionomer (control group): More dye penetration was observed in the dentinal (D) border compared with the enamel (E) margin (30x magnification).

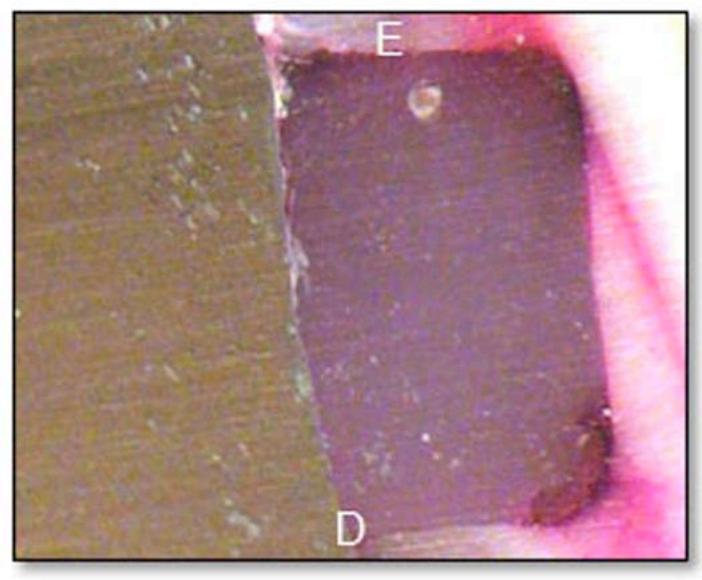

Figure 4. Resin-modified glass ionomer (test groups): Postoperative bleaching increased the microleakage of the enamel margin $(E)$; the highest degree of microleakage was obtained in these groups (30x magnification). were observed between the two types of restorations regarding dentinal margins (Wilcoxon $\mathrm{p}=0.091)$ (Table 1 and Figure 1$)$.

A comparison of microleakage of composite restorations within each group showed no significant differences between enamel and dentinal margins (Wilcoxon $p=0.102$ ) in the control subgroup (C1), but there were significant differences between enamel and dentinal margins in each of the experimental composite subgroups (Wilcoxon C2: $p=0.010, C 3: p=0.032$, and $C 4: p=0.10$ ).

A comparison of microleakage of resin-modified glass ionomer restorations revealed the degree of microleakage for the dentinal margin was statistically more than for the enamel margin (Wilcoxon $p=0.10$ ) in the control group. However, in the other experimental resin-modified glass ionomer subgroups, an increase in the dye penetration in the enamel margins after bleaching caused a statistically similar microleakage in enamel and dentinal margins (Wilcoxon G2: $p=0.83$, G3: $p=0.91$, and $G 4: p=0.317$ ) (Figure 4).

\section{Discussion}

The purpose of this in vitro study was to evaluate the effect of different time intervals of postoperative vital bleaching procedures on the degree of microleakage of recently placed resin composite and resin-modified glass ionomer restorations in Class V cavity preparations.

The first null hypothesis of this research was accepted because findings showed $15 \%$ carbamide peroxide did not adversely affect the seal of the enamel margin of composite restorations. The application of bleaching agents over previously placed resin composite restorations has shown little effect on composite mechanical properties. ${ }^{16,17}$ The use of oxidizing agents could cause chemical softening, erosion, or degradation of resinous materials; however, no changes were observed with respect to fractures in the surface of the composite. ${ }^{18}$

Ulukapi et al. ${ }^{12}$ demonstrated more microleakage in a postoperative bleached enamel/composite interface. This result differs from the present study, while a recent study done by White et al. ${ }^{15}$ showed postoperative bleaching with $20 \%$ carbamide 
peroxide gel, $6 \% \mathrm{H}_{2} \mathrm{O}_{2}$, and $19 \%$ percarbonate gel had no effect on microleakage of composite resin. However, these studies did not compare the effect of different elapses in time between restoration placement and following bleaching. An SEM photomicrograph of a postoperative bleached enamel/resin composite interface revealed cohesive fractures in enamel. ${ }^{18}$ Such changes in enamel margins are not likely the main cause of an increase in microleakage because there was no correlation between the bonding and microleakage..$^{19}$

Tooth whitening treatments can possibly alter dentinal properties. ${ }^{20}$ In the present study the application of the bleaching gel at the bonded dentin/composite interface did not affect the sealing ability of resin composite restorations at different time intervals of postoperative bleaching. Therefore, the second hypothesis was also accepted.

Crim $^{14}$ demonstrated a carbamide peroxide agent adversely affected the marginal sealing ability of both enamel and dentinal margins of a previously placed resin composite when used in combination with the third generation of dentin bonding agents. These controversial results are probably due to the effective sealing ability now obtained with the newer generation of dentin adhesives $^{21}$ that were not used in the Crim study. However, the new dentin adhesives cannot completely eliminate dentinal microleakage after bleaching. The results of the present study regarding the comparison between enamel and dentinal margins in experimental groups of composite restorations were consistent with other studies, ${ }^{, 22-24}$ therefore, the third hypothesis for composite was rejected.

The first and second null hypotheses of this study regarding microleakage of glass ionomer were accepted because this study found no significant differences in enamel or dentinal marginal microleakage among groups in glass ionomer restorations. One previous study on bonded resin composite on enamel showed the least favorability relative to microleakage compared to the compomer and resin-modified glass ionomer following exposure to various concentrations of dental bleaching agents. ${ }^{13}$
This is in contrast with the results of the present study because the control group showed more microleakage in dentinal margins than in enamel margins. However, postoperative bleaching caused an increase in the dye penetrations in enamel margins of experimental groups. This resulted in similarity of microleakage between enamel and dentinal margins after bleaching.

The findings of this study on the effect of postoperative bleaching on dentin/glass ionomer interfaces could not be compared to those of other studies due to the lack of available data from the research using a similar methodology. A reversible breaking and reforming of the calcium carboxyl complex in the presence of artificial saliva and the forming of a dynamic bond $^{25}$ is probably a reason for similarity among groups regarding dentinal margin microleakage. A previous study showed that high and low concentrated bleaching agents did not influence fluoride release and significant dissolution of resin-modified glass ionomer. ${ }^{26}$

The findings of this study showed bleaching procedures are probably indicated for patients with recently placed resin composite restorations. Enamel/composite interfaces are not affected by bleaching according to the microleakage test. However, special care must be taken at dentin/ composite interfaces. The findings of this study suggest the following:

1. Rebond ${ }^{27}$ the dentinal margins of resin composite restorations with a low-viscosity resin after the end of bleaching procedures for reducing microleakage instead of replacing them.

2. Avoid using a resin-modified glass ionomer before dental bleaching procedures because of the increased microleakage associated with it.

\section{Conclusions}

Within the limitations of this in vitro study, it can be concluded that postoperative bleaching with $15 \%$ carbamide peroxide could increase microleakage in dentinal margins of composite restorations and in enamel margins of resinmodified glass ionomer restorations. 


\section{Clinical Significance}

Rebonding of resin composite restorations should be considered following bleaching with 15\% carbamide peroxide in order to reseal the margins. Resin-modified glass ionomer is not suitable as a filling material before bleaching because of its susceptibility to increased microleakage.

\section{References}

1. Turker SB, Biskin T. Effect of three bleaching agents on the surface properties of three different esthetic restorative materials. J Prosthet Dent. 2003; 89(5):466-73.

2. Dahl JE, Pallesen U. Tooth bleaching-a critical review of the biological aspects. Crit Rev Oral Biol Med. 2003; 14(4):292-304.

3. Bitter NC, Sanders JL. The effect of four bleaching agents on the enamel surface: A scanning electron microscopic study. Quintessence Int. 1993; 24:817-24.

4. Attin T, Muller T, Patyk A, Lennon AM. Influence of different bleaching systems on fracture toughness and hardness of enamel. Oper Dent. 2004; 29(2):188-95.

5. Attin T, Kocabiyik M, Buchalla W, Hannig C, Becker K. Susceptibility of enamel surfaces to demineralization after application of fluoridated carbamide peroxide gels. Caries Res. 2003; 37(2):93-9.

6. Ghavamnasiri M, Abedini S, Mehdizadeh Tazangi A. Effect of different time periods of vital bleaching on flexural strength of the bovine enamel and dentin complex. J Contemp Dent Pract. 2007; 8(3):21-8.

7. Turker SB, Biskin T. The effect of bleaching agents on the microhardness of dental aesthetic restorative materials. J Oral Rehabil. 2002; 29(7):657-61.

8. Langsten RE, Dunn WJ, Hartup GR, Murchison DF. Higher-concentration carbamide peroxide effects on surface roughness of composites. J Esthet Restor Dent. 2002; 14(2):92-6.

9. Ghavamnasiri $\mathrm{M}$, Bidar $\mathrm{M}, \operatorname{Rad} \mathrm{AH}$, Namazikhah MS. The effect of 16 percent carbamide peroxide on enamel staining susceptibility. J Calif Dent Assoc. 2006; 34(11):873-6.

10. Campos I, Briso AL, Pimenta LA, Ambrosano G. Effects of bleaching with carbamide peroxide gels on microhardness of restoration materials. J Esthet Restor Dent. 2003; 15(3):175-82.

11. Attin T, Hannig C, Wiegand A, Attin R. Effect of bleaching on restorative materials and restorations - a systematic review. Dent Mater. 2004; 20(9):852-61.

12. Ulukapi H, Benderli Y, Ulukapi I. Effect of pre- and post-operative bleaching on marginal leakage of amalgam and composite restorations. Quintessence Int. 2003; 34(7):5058.

13. Owens BM, Rowland CC, Brown DM, Covington JS 3rd. Postoperative dental bleaching: effect of microleakage on Class $\mathrm{V}$ tooth colored restorative materials. J Tenn Dent Assoc. 1998; 78(4):36-40.

14. Crim GA. Post-operative bleaching: effect on microleakage. Am J Dent. 1992; 5(2):109-12.

15. White DJ, Duschner H, Pioch T. Effect of bleaching treatments on microleakage of Class I restorations. J Clin Dent. 2008; 19(1):33-6.

16. García-Godoy F, García-Godoy A, GarcíaGodoy F. Effect of bleaching gels on the surface roughness, hardness, and micromorphology of composites. Gen Dent. 2002; 50(3):247-50.

17. Yap AU, Wattanapayungkul P. Effects of in-office tooth whiteners on hardness of tooth-colored restoratives. Oper Dent. 2002; 27(2):137-41.

18. Cavalli V, de Carvalho RM, Giannini M. Influence of carbamide peroxide-based bleaching agents on the bond strength of resinenamel/dentin interfaces. Braz Oral Res. 2005; 19(1):23-9.

19. Heintze SD. Systematic reviews: I. The correlation between laboratory tests on marginal quality and bond strength. II. The correlation between marginal quality and clinical outcome. J Adhes Dent. 2007; 9 Suppl 1: 77-106.

20. Dezotti MS, Souza MH Jr, Nishiyama CK. [Evaluation of $\mathrm{pH}$ variation and cervical dentin permeability in teeth submitted to bleaching treatment]. Pesqui Odontol Bras. 2002; 16(3):263-8.

21. Yazici AR, Baseren M, Dayangaç B. The effect of current-generation bonding systems on microleakage of resin composite restorations. Quintessence Int. 2002; 33(10):763-9.

22. Owens BM, Johnson WW. Effect of single step adhesives on the marginal permeability of Class V resin composites. Oper Dent. 2007; 32(1):67-72. 
23. Owens BM, Johnson WW. Effect of insertion technique and adhesive system on microleakage of Class $\mathrm{V}$ resin composite restorations. J Adhes Dent. 2005; 7(4):303-8.

24. Ghavamnasiri M, Moosavi H, Tahvildarnejad N. Effect of centripetal and incremental methods in Class II composite resin restorations on gingival microleakage. J Contemp Dent Pract. 2007; 8(2):113-20.

25. Brook IM, Craig GT, Lamb DJ. Initial in-vivo evaluation of glass-ionomer cements for use as alveolar bone substitutes. Clin Mater. 1991; 7(4):295-300.

26. Robertello FJ, Meares WA, Gunsolley JC, Baughan LW. Effect of peroxide bleaches on fluoride release of dental materials. Am J Dent. 1997; 10(6):264-7.

27. Tjan $\mathrm{AH}$, Tan DE. Microleakage at gingival margins of Class $V$ composite resin restorations rebonded with various lowviscosity resin systems. Quintessence Int. 1991; 22(7):565-73.

\section{About the Authors}

Horieh Moosavi, DDS, MS

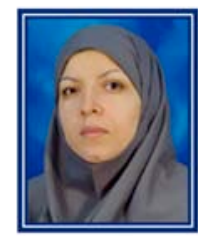

Dr. Moosavi is an Assistant Professor in the Department of Operative Dentistry of the School of Dentistry, Dental Research Center, at Mashhad University of Medical Sciences in Mashhad, Iran. Her research interests include microleakage, adhesive systems, and tooth-colored restorative materials. She is a member of the Iranian Academy of Cosmetic Restorative Dentistry in Iran and an IADR member in the USA. She has been the corresponding author for this article.

e-mail: dentist $57 @$ yahoo.com or moosavih@mums.ac.ir
Marjaneh Ghavamnasiri DDS, MS (Corresponding Author)

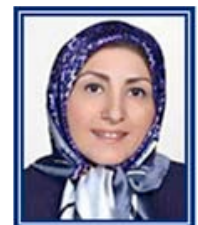

Dr. Ghavamnasiri is a Professor and the Director of the Postgraduate Program in the Department of Restorative Dentistry of the Mashhad Dental School and Dental Research Center at Mashhad University of Medical Sciences in Mashhad, Iran.

e-mail: Ghavamnasirim@mums.ac.ir

Vahideh Manari, DDS

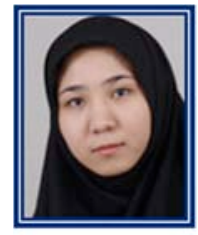

Dr. Manari is a student in the Department of Operative Dentistry of the School of Dentistry, Dental Research Center at Mashhad University of Medical Sciences in Mashhad, Iran. Her research interests include cosmetic dentistry, dental materials and microleakage, and tooth whitening.

e-mail: vmanari@yahoo.com

\section{Acknowledgement}

This study was supported by a grant from the Dental Research Center and the Research Council of Mashhad University of Medical Sciences in Mashhad, Iran. 